\title{
Biomimetic nanoparticles: preparation, characterization and biomedical applications
}

REVIEW

\author{
This article was published in the following Dove Press journal: \\ International Journal of Nanomedicine \\ 31 March 2010 \\ Number of times this article has been viewed
}

\section{Ana Maria Carmona-Ribeiro \\ Biocolloids Lab, Departamento de Bioquímica, Instituto de Química, Universidade de São Paulo, São Paulo, Brazil}

\begin{abstract}
Mimicking nature is a powerful approach for developing novel lipid-based devices for drug and vaccine delivery. In this review, biomimetic assemblies based on natural or synthetic lipids by themselves or associated to silica, latex or drug particles will be discussed. In water, self-assembly of lipid molecules into supramolecular structures is fairly well understood. However, their self-assembly on a solid surface or at an interface remains poorly understood. In certain cases, hydrophobic drug granules can be dispersed in aqueous solution via lipid adsorption surrounding the drug particles as nanocapsules. In other instances, hydrophobic drug molecules attach as monomers to borders of lipid bilayer fragments providing drug formulations that are effective in vivo at low drug-to-lipid-molar ratio. Cationic biomimetic particles offer suitable interfacial environment for adsorption, presentation and targeting of biomolecules in vivo. Thereby antigens can effectively be presented by tailored biomimetic particles for development of vaccines over a range of defined and controllable particle sizes. Biomolecular recognition between receptor and ligand can be reconstituted by means of receptor immobilization into supported lipidic bilayers allowing isolation and characterization of signal transduction steps. Keywords: cationic lipid, phospholipids, bilayer fragments, vesicles, silica, polymeric particles, antigens, novel cationic immunoadjuvants, drugs
\end{abstract}

\section{Introduction}

Particles are important in pharmaceutical and biomedical research since their size scale can be similar to that of proteins or DNA. They can mimic structural and functional aspects of viruses, bacteria and other biological assemblies and are currently being used in: imaging, ${ }^{1}$ biosensing, ${ }^{2}$ gene and drug delivery ${ }^{3}$ and vaccines. ${ }^{4,5}$ On the other hand, cationic lipids can be combined with negatively charged biomolecules or biological structures. Silica, ${ }^{6}$ latex, ${ }^{7}$ or hydrophobic drug particles ${ }^{8}$ have been coated with cationic lipids and characterized by means of adsorption isotherms, mean particle size from dynamic light scattering, surface potential analysis and colloidal stability. Properties of the intervening medium such as $\mathrm{pH}$ and ionic strength were systematically varied for achieving optimal lipid bilayer deposition and colloid stability. ${ }^{6,9}$ Polystyrene sulfate (PSS) nanoparticles covered with a dioctadecyldimethylammonium bromide (DODAB) bilayer ${ }^{10}$ were used for adsorption of serum proteins, ${ }^{11}$ cholera toxin, ${ }^{11}$ Taenia crassiceps antigens, ${ }^{12,13}$ recombinant proteins, ${ }^{13,14}$ polysaccharides ${ }^{15-17}$ and giant DNA. ${ }^{18}$ Similarly, lipid assemblies such as liposomes, vesicles, solid lipid nanoparticles and lipidic bilayer fragments (BF) or disks are as versatile as particles. Alec Bangham produced the first liposomes in 1965 in Cambridge UK. ${ }^{19}$ The liposome "membrane" model prepared from phospholipids has lead to much of our present 
knowledge on membrane properties. In addition, a variety of bilayer structures formed by dialkyldimethylammonium halides ${ }^{20}$ and other synthetic amphiphiles ${ }^{21-24}$ were introduced to mimic membrane properties furnishing unique opportunities to investigate structure-function relationships. Since the major requirement to form a supramolecular assembly of the bilayer type was an approximately cylindrical amphiphilic molecule with a geometric parameter between 0.5 and $1.0,{ }^{25}$ not only natural phospholipids were prone to form bilayers. Structural and functional aspects of biological membranes were also copied in a variety of biomimetic systems. Bilayers were the preferential supramolecular assembly for several synthetic amphiphiles as dialkyldimethylammonium bromide or chloride, ${ }^{20}$ sodium dihexadecylphosphate ${ }^{22,26,27}$ and many other molecules. ${ }^{28,29}$ However, lipid BF or disks remained as a much less explored bilayer assembly. Lately, our group has been developing novel formulations for hydrophobic drugs or vaccines based on these structures. Amphotericin B solubilized at the rim of DODAB BF provided a novel formulation with excellent activity against systemic candidiasis in mice at low drug dose ${ }^{30,31}$ with low nephrotoxicity. ${ }^{32} \mathrm{BF}$ have also been useful to cover particles such as silica, latex or insoluble drug particles with lipids. ${ }^{33,34}$ This mini-review aims at an overview on preparation, characterization and biomedical applications for lipid-based biomimetic particles.

\section{Lipid BF or disks}

Upon probe sonication of aqueous egg yolk lecithin dispersions, the high kinetic energy given by the sonicator to the lipid particles, caused their breaking down on colliding with each other. ${ }^{35}$ The collisions completely disrupted the multilamellar particles into short-lived bilayer fragments, which then reaggregated to form single-shelled vesicles of roughly uniform size. ${ }^{35}$ From this early study up to now, discs have been reported for a variety of amphiphiles and lipids in aqueous dispersions over a broad range of experimental conditions. ${ }^{10,36}$ They were found from self-assembly of lipids and proteins, ${ }^{37-39}$ lipids and micelle-forming compounds ${ }^{40,41}$ lipids and hydrophilic polymers such as polyethylene-glycol lipids (PEGylated lipids) (2,43 $^{4}$ or charged lipids dispersed by probe sonication. ${ }^{27,44-46}$ The major repulsive interactions preventing fusion of lipid BF and discs in dispersion were electrostatic, steric and/or eletrosteric. In particular, probe sonication of the synthetic and cationic lipid dioctadecyldimethylammonium bromide (DODAB) can yield disrupted vesicles: the bilayer fragments, BF, or disks. ${ }^{10}$ The existence of BF in aqueous dispersions of sodium dihexadecylphosphate, or dioctadecyldimethylammonium bromide or chloride obtained by probe sonication has been supported by the following evidences: (i) osmotic non-responsiveness of the dispersion indicative of absence of inner vesicle compartment; ${ }^{47}$ (ii) transmission electron microscopy (TEM) micrographs with electronic staining; ${ }^{27}$ (iii) cryo-TEM micrographs; ${ }^{45}$ (iv) fluid and solid state coexistence and complex formation with oppositely charged surfactant; ${ }^{48}(\mathrm{v})$ solubilization of hydrophobic drugs at the borders of DODAB bilayer fragments, which does not occur for DODAB closed bilayer vesicles. ${ }^{49,50}$ They differ from the closed vesicles by providing hydrophobic borders at their edges that are absent in closed bilayer systems such as vesicles or liposomes. Under conditions of low ionic strength, due to electrostatic repulsion, the charged BF remain colloidally stable in aqueous dispersions. These $\mathrm{BF}$ are not micelles; due to its cylindrical molecular shape DODAB or sodium dihexadecylphosphate (DHP) molecules self-assemble as bilayers. ${ }^{51,52}$ Figure 1 shows BF from different lipids.

\section{The interaction between particles and bilayers for vaccines}

The interaction between one bilayer vesicle and two microspheres considering vesicles and particles of similar sizes can be electrostatic, electrodynamic (van der Waals) and/or hydrophobic. ${ }^{6,753-61}$ Figure 2 schematically illustrates possible interactions and assemblies.

In the first step (step 1), electrostatic and/or van der Waals and/or hydrophobic attraction leads to aggregation of a vesicle and a particle. These same interaction forces may disrupt the vesicle bilayer and promote bilayer adsorption onto the microsphere (step 2) and/or further aggregation with the other microsphere (step $2^{\prime}$ ). The adsorbed bilayer may attract the second microsphere (step 3). The hydrophobic interaction between an eventually hydrophobic surface and the hydrocarbon chains in the bilayer may completely destroy the bilayer structure flip-flopping the hydrocarbon chains onto the particle surface and generating a monolayered coverage on each microsphere (step 4). Lipid deposition from lipidic vesicles onto a solid surface would be determined initially by the classical combination of a repulsive force arising from the interaction of the electrical double layers associated with the vesicle and the surface and the attractive dispersion force between the vesicle and the solid. Vesicles are not, however, permanent rigid structures, and depending on their size, chemical composition, physical state of the bilayer and aqueous medium composition they can distort, aggregate, disrupt and fuse with each other. Deposition of vesicles onto a solid surface could give rise to any particular one or a combination 
A

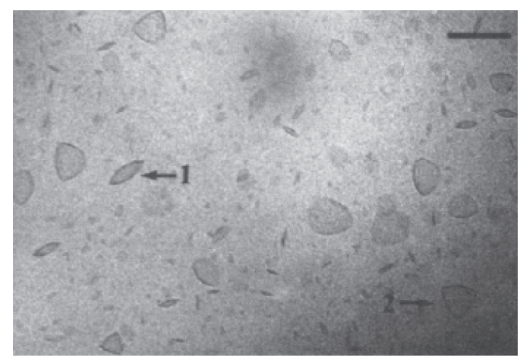

C

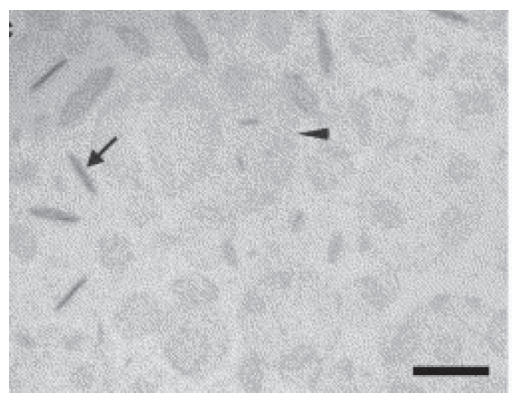

B

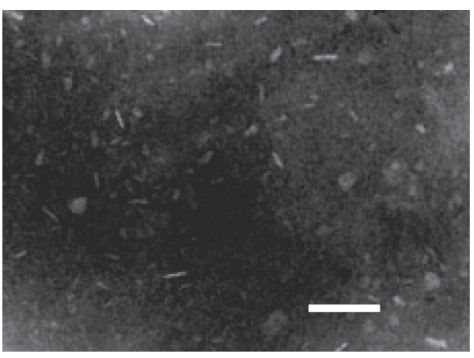

D

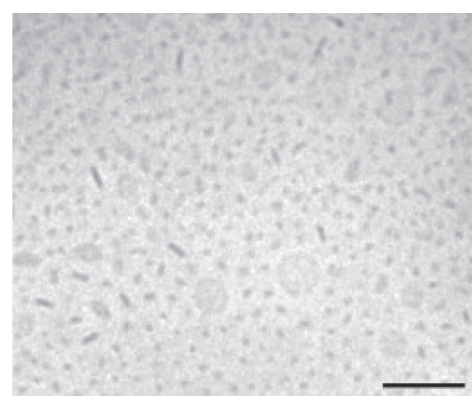

Figure I A) Lipid BF of dioctadecyldimethylammonium bromide (DODAB) ${ }^{45}$ or B) sodium dihexadecylphosphate (DHP) ${ }^{27}$ or C) DSPC/cholesterol/PEG-DSPE(5000) mixtures at 12 mol\% PEG-DSPE(5000) ${ }^{42}$ or D) DSPC: cholesterol: ceramide-PEG5000 carrying bacteriorhodopsin. ${ }^{43}$

Notes: With exception of micrograph in B) which was obtained by TEM after negatively staining the sample, all micrographs were obtained by cryo-TEM. In C), disks were observed edge-on (arrow) or face-on (arrow head). Bars denote 100 nm. Copyright @ 1995 and I 99 I American Chemical Society; (c) 2005 and 2007 Elsevier. Adapted with permission from Carmona-Ribeiro AM, Castuma CE, Sesso A, Schreier S. Bilayer structure and stability in dihexadecyl phosphate dispersions.J Phys Chem. 199I;95:536I-5366. Johansson E, Engvall C, Arfvidsson M, Lundahl P, Edwards K. Development and initial evaluation of PEG-stabilized bilayer disks as novel model membranes. Biophys Chem. 2005; I 13:183-192. Johansson E, Lundquist A, Zuo S, Edwards K. Nanosized bilayer disks: attractive model membranes for drug partition studies. Biochim Biophys Acta. 2007; 1768:1518-1525. Andersson M, Hammarstrom L, Edwards K. Effect of bilayer phase transitions on vesicle structure, and its influence on the kinetics of viologen reduction. J Phys Chem. 1995;99(39): 14531-14538.

Abbreviations: DHP, sodium dihexadecylphosphate; DODAB, dioctadecyldimethylammonium bromide; DSPE, distearoylphosphatidylethanolamine; PEG, polyethyleneglycol; TEM, transmission electron microscopy.

of these processes. Unilamellar phosphatidylcholine vesicles were reported to break open and adhere to a mica surface to form a bilayer coating. ${ }^{62}$

Phospholipid monolayers with lipid haptens inserted were supported by hydrophobic glass and useful for specific adherence of macrophages and cell surface recognition studies, but did not serve as hosts for transmembrane proteins. ${ }^{63}$

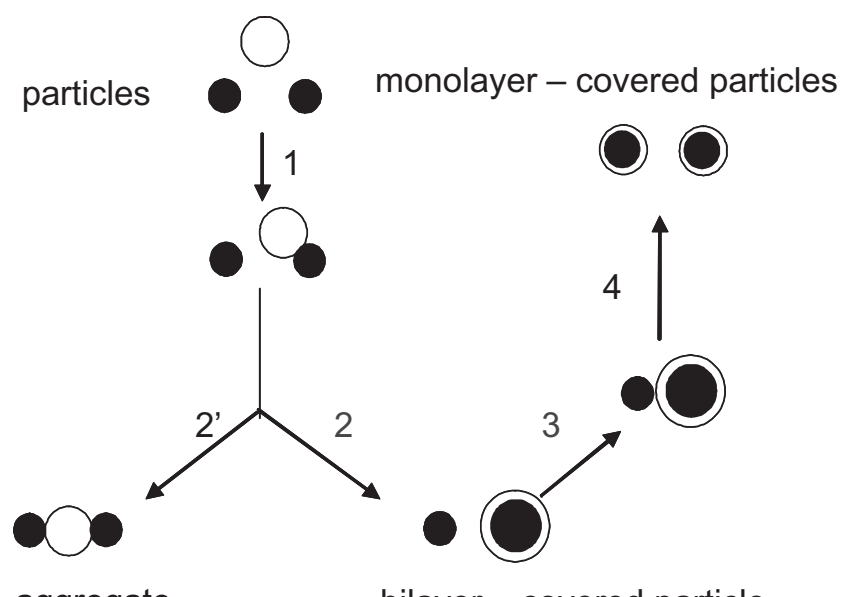

aggregate

bilayer - covered particle

Figure 2 The interaction between one bilayer vesicle and two particles. ${ }^{6,7,53-61}$ Copyright (C) 1999 Elsevier. Adapted with permission from Carmona-Ribeiro AM, Lessa MM. Interactions between bilayer vesicles and latex. Colloids SurfA. 1999;153:355-36I.
Dipalmitoylphosphatidylcholine (DPPC) and phosphatidylinositol (PI) from vesicles adsorbed onto negatively charged ballotini (hydrophobic) glass beads as a monolayer with their head groups uppermost. ${ }^{64}$

The easiest method for preparing high quality phospholipid bilayers on a flat hydrophilic surface was the direct fusion of small unilamellar vesicles. ${ }^{65}$ This method stemmed from making unilamellar membranes on glass coverslips for spectroscopic studies. ${ }^{65}$ Phospholipid fusion at the hydrophilic surface such as freshly cleaved mica could be induced at elevated temperatures for those lipids of higher transition temperature with traces of divalent cations such as $\mathrm{Ca}^{2+}$. The other method for preparing supported membranes of biological interest was the controlled transfer of monolayers to the surface using the Langmuir. trough. Using this method the content in each leaflet was easily controlled. ${ }^{66}$ The main advantages of the vesicle fusion method seemed to be simplicity and the most natural lateral pressure in the bilayer in comparison to the lateral pressures obtained with the Langmuir trough. However, the content in each leaflet could not be controlled using fusion. Palmitoyloleoylphosphatidylcholine (POPC) vesicles without major protruding molecular moieties spread on a glass surface and formed 
a supported planar bilayer. ${ }^{67}$ In contrast, Escherichia coli (E. coli) lipid vesicles adsorbed as entire vesicles to the surface forming a supported vesicle layer on glass. ${ }^{67}$ The difference in behavior upon deposition on glass was due to chemical structure of $E$. coli lipids. Lipopolysaccharides from $E$. coli are bulky and have strongly hydrated polar heads. Their vesicles simply adhered and formed a supported vesicle layer on glass. ${ }^{67}$ Fusion in-between vesicles attached to the surface was prevented by steric repulsion. ${ }^{67}$ For DPPC and DSPC bilayers on hydrophilic silicon/water interface, single and double bilayers have been prepared and characterized via neutron reflectivity. ${ }^{68}$ This technique investigated the structure, hydration and roughness of the layers and allowed to determine the distance between two deposited bilayers. ${ }^{68}$ The outermost bilayer was highly hydrated and floated at 2 to $3 \mathrm{~nm}$ above the first one. ${ }^{68}$ Adhesion of a DODAB vesicle layer onto the rough and highly hydrated surface of cells was electrostatically driven. Cationic vesicles at low ionic strength surrounded the bacterial cell as a vesicle layer. ${ }^{69}$ Absence of DODAB vesicle disruption upon interaction with the bacteria was depicted from absence of $\left[{ }^{14} \mathrm{C}\right]$-sucrose leakage from large vesicles in experiments where this marker was used to label the inner water compartment of the vesicles. ${ }^{70}$ Given the quaternary ammonium moiety of the DODAB molecule, its antimicrobial effect was systematically evaluated and its differential cytotoxicity established as illustrated in Table 1.

In spite of its dose dependent-toxicity, DODAB induced delayed-type hypersensibility (DTH), a marker for cellmediated immune responses. This interesting property allowed DODAB to find many uses as an efficient immunoadjuvant mainly for veterinary uses but also in humans in a few instances. ${ }^{13,74-79}$ Supramolecular assemblies of DODAB BF by themselves or after interaction with supporting particles were recently combined with three different model antigens in separate and tested as immunoadjuvants. ${ }^{13}$ DODAB-based immunoadjuvants carrying antigens at reduced DODAB dose $(0.01-0.1 \mathrm{mM})$ induced superior DTH responses in mice in comparison to alum. Thus, the cationic immunoadjuvant was either reduced to a single-component, nanosized system - DODAB BF - or was a dispersion of cationic particles with controllable nature and size as obtained after covering silica or polystyrene sulfate latex (PSS) with a cationic DODAB bilayer. DODAB BF interacted with proteins both via the hydrophobic effect and the electrostatic attraction at low ionic strength. DODAB based adjuvants exhibited good colloid stability while complexed with the antigens, complete absence of toxicity in mice (ie, local or general reactions) and a remarkable induction of Th1 immune response at reduced doses of cationic and toxic DODAB lipid. DODAB vesicle disruption by probe sonication at low ionic strength (0.1-5.0 mM monovalent salt) produced DODAB $\mathrm{BF}$ which remained electrostatically stabilized in dispersion by the electrostatic repulsion in between fragments. DODAB BF also interacted with oppositely charged particles such as silica or polystyrene sulfate (PSS) latex to produce the cationic particulates. Figure 3 schematically introduced the novel cationic immunoadjuvants based on reduced DODAB doses and their compared DTH response. ${ }^{12-14}$

The final DODAB concentration required to cover all particles with a bilayer can be easily calculated from total surface area for particles and bilayers and from the mean molecular area for the lipid at the air-water interface. , $^{6,11,56}$ Sizing, zeta-potentials and polydispersity index for the novel cationic adjuvants as compared to the similarly cationic $\mathrm{Al}(\mathrm{OH})_{3}$ evidenced a superior colloid stability in contrast to the one exhibited by alum. ${ }^{13,14}$ Table 2 illustrates the physical properties of DODAB BF, PSS/DODAB and silica/DODAB used in Figure 3 for antigen presentation.

Chemical, biological (eg, engineered viruses and bacteria), polymeric or liposomal adjuvants have been developed and tested for vaccines. ${ }^{4,5,80-83}$ However, most of them induced

Table I Differential cytotoxicity of DODAB against some eukaryotic* and prokaryotic cells**

\begin{tabular}{llll}
\hline Cell type & Viable cells $/ \mathbf{m L}$ & [DODAB] $_{50 \% \text { survival }} / \mathbf{m M}$ & Ref. \\
\hline Normal Balb-c 3T3 mouse fibroblasts* & $10^{4}$ & 1.000 & 71 \\
SV40-transformed SVT2 mouse fibroblasts* & $10^{4}$ & 1.000 & 71 \\
C. albicans* & $2 \times 10^{6}$ & 0.010 & 72 \\
E. coli** & $2 \times 10^{7}$ & 0.028 & 70,73 \\
S. typhimurium** & $2 \times 10^{7}$ & 0.010 & 73 \\
P. aeruginosa** & $3 \times 10^{7}$ & 0.005 & 73 \\
S. aureus** & $3 \times 10^{7}$ & 0.006 & 73 \\
\hline
\end{tabular}

Abbreviation: DODAB, dioctadecyldimethylammonium bromide. 


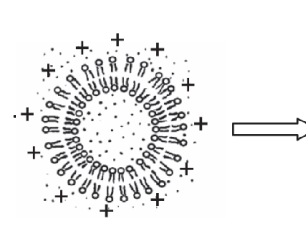

DODAB vesicle

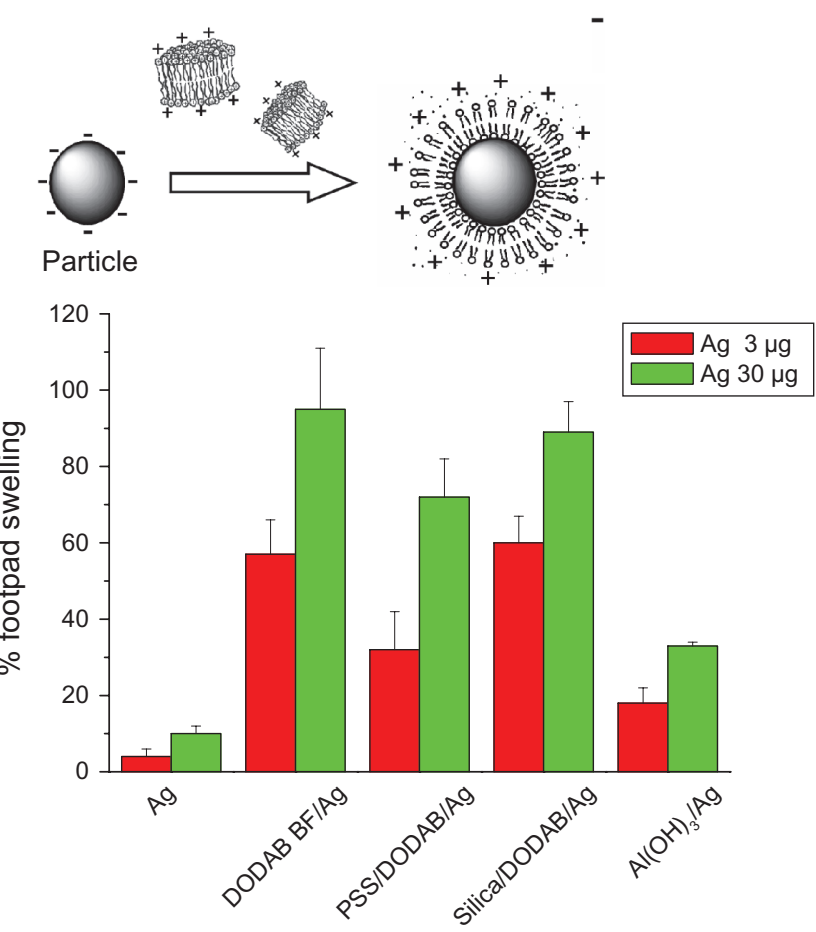

Figure 3 Superior performance of novel DODAB-based adjuvants inducing DTH in mice as compared to alum. The same antigen $(\mathrm{Ag})$ carried by each adjuvant was used for immunization. $\mathrm{Ag}$ was carried by DODAB BF at $0.1 \mathrm{mM}$ DODAB (DODAB BF/Ag) or by $\mathrm{PSS} / \mathrm{DODAB}$ or silica/DODAB particles at 0.01 or $0.05 \mathrm{mM}$ DODAB (PSS/DODAB/Ag or silica/DODAB/Ag), respectively, or by alum $\left(\mathrm{Al}(\mathrm{OH})_{3} / \mathrm{Ag}\right)$. After immunization, elicitation of the swelling response was done by injecting $\mathrm{Ag}$ alone in the footpad so that \% footpad swelling was measured in comparison to alum. Copyright (C) 2007,2009 Elsevier. Adapted with permission from Lincopan N, Espíndola NM,Vaz AJ, Carmona-Ribeiro AM. Cationic supported lipid bilayers for antigen presentation. In.J Pharm. 2007;340:2 16-222. Lincopan N, Espíndola NM,VazAJ, et al. Novel immunoadjuvants based on cationic lipid:preparation, characterization and activity in vivo. Vaccine. 2009;27:5760-577I. Lincopan N,Santana MRA Faquim-Mauro E, da Costa MHB, Carmona-Ribeiro AM. Silica-based cationic bilayers as immunoadjuvants. BMC Biotechnol. 2009;9:article 5.

Abbreviations: DODAB, dioctadecyldimethylammonium bromide; PSS, polystyrene sulfate; DTH, delayed-type hypersensibility; BF, bilayer fragments.

side effects and/or showed a lack of universality for different antigens or routes of administration. At present the only adjuvant licensed worldwide for humans is represented by aluminum salts, mainly aluminum hydroxide and aluminum phosphate. ${ }^{84,85}$ They elicit high and long lasting antibody titers and Th2 type responses but are poor inducers of cytotoxic $\mathrm{T}$ lymphocytes (CTLs), the most important cellular defense against infectious diseases caused by intracellular pathogens (eg, HIV and Mycobacterium tuberculosis) and tumors. ${ }^{84}$ Furthermore, alum adjuvants can induce occasional local reactions. ${ }^{86,87}$ and production of immunoglobulin $\mathrm{E}(\mathrm{IgE})$ both associated with some allergic reactions in humans. ${ }^{88,89} \mathrm{In}$ addition to Alum, MF59, ${ }^{90-95}$ virosomes $^{96-98}$ and L-tyrosine ${ }^{99}$ represented new and safe adjuvants and carrier systems recently licensed in some countries for human use.

Particles are taken up by antigen presenting cells (APC) more effectively than soluble antigen. ${ }^{100,101}$ Optimal APC uptake of positively charged particles with diameters of $500 \mathrm{~nm}$ and below was reported. ${ }^{102}$ Furthermore, particles with a positive charge showed higher internalization into human breast cancer cells than those with negative charge, while the degree of internalization of the positively and negatively charged nanoparticles into human umbilical vein endothelial cells was almost the same. ${ }^{103}$ Particles coated by cationic lipid were optimized regarding bilayer deposition. ${ }^{6,9,12,18}$ This was possible from systematic studies of effects of ionic strength and concentrations for particles and cationic lipid. Due to the microbicidal effect of cationic lipids and surfactants, ${ }^{104}$ cationic particles turned out to be extremely toxic to bacteria, a major problem while trying to transform these microorganisms by means of cationic particle/DNA assemblies. ${ }^{18}$ The bacteria cannot be genetically modified if they die. Silica, ${ }^{6,56,57,61}$ latex ${ }^{7,105}$ or hydrophobic drug particles ${ }^{4,33,49}$ have been coated with cationic lipids. Although DODAC or DHP electrostatically adsorbed to oppositely charged polystyrene microspheres, forming homodisperse bilayer-covered lattices, this took place only over a certain range of low lipid concentrations. ${ }^{7,12,53,54}$ Beyond bilayer deposition, there was vesicle adhesion to the bilayer-covered latex..$^{53}$ Using radiolabeled D-glucose inside the cationic vesicles at very low ionic strength, cationic liposome adsorption was accompanied of vesicle disruption evidencing formation of a bilayer on the solid particle surface.$^{53} \mathrm{~A}$ series of monodisperse PSS dispersions (76-412 nm mean diameter) were coated with DODAB bilayers so that the biomimetic particles are available over a range of controllable sizes. ${ }^{18,54}$ The zeta-potential of these bilayer-covered particles in water remained constant (and positive) over the entire range of sizes tested.

Whereas polystyrene microspheres have a hydrophobic surface, silica particles are good models for hydrophilic surfaces. Silica interacts with erythrocytes, lysosomes, macrophage plasma membranes and liposomes ${ }^{106}$ but the mechanism of the interaction between silica and phospholipid membranes is still controversial. The main possibilities are: 1) silica particles binding dipalmitoylphosphatidylcholine (DPPC) through hydrogen bonds between $\mathrm{Si}-\mathrm{OH}$ and $\mathrm{O}=\mathrm{P}$ - groups; 2) tetraalkylammonium groups at the extracellular region of the erythrocyte membrane forming 
Table 2 Physical properties of the novel cationic immunoadjuvants in a ${ }^{\mathrm{mM} \mathrm{NaCl}}(\mathrm{pH} 6.3)$ or ${ }^{\mathrm{b}} 5 \mathrm{mM}$ Tris $\mathrm{HCl}(\mathrm{pH} 7.4)$ at $5 \times 10^{9} \mathrm{PSS}$ particles $/ \mathrm{ml}$ or $0.1 \mathrm{mg} / \mathrm{ml}$ silica or $0.1 \mathrm{mg} / \mathrm{mlAl}(\mathrm{OH})_{3}$. Copyright $\odot 2009$ Elsevier. Adapted with permission from Lincopan N, Espíndola NM, Vaz AJ, et al. Novel immunoadjuvants based on cationic lipid: preparation, characterization and activity in vivo.Vaccine. 2009;27:5760-577I.

\begin{tabular}{|c|c|c|c|c|}
\hline Dispersion & DODAB/mM & Mean diameter/nm & Zeta-potential/mV & Polydispersity index \\
\hline $\mathrm{DODAB} \mathrm{BF}^{\mathrm{a}}$ & 1.0 & $73 \pm 1$ & $42 \pm 2$ & $0.240 \pm 0.01$ \\
\hline PSS $^{a}$ & - & $236 \pm 4$ & $-6 I \pm 1$ & $0.130 \pm 0.03$ \\
\hline PSS/DODAB ${ }^{a}$ & 0.01 & $246 \pm 3$ & $44 \pm 3$ & $0.085 \pm 0.03$ \\
\hline $\mathrm{Al}(\mathrm{OH})_{3}{ }^{a}$ & - & $458 \pm 3$ & $28 \pm 3$ & $0.191 \pm 0.04$ \\
\hline DODAB BF & 1.0 & $74 \pm 1$ & $33 \pm 5$ & $0.270 \pm 0.04$ \\
\hline Silica $^{\mathrm{b}}$ & - & $294 \pm 2$ & $-47 \pm 2$ & $0.180 \pm 0.02$ \\
\hline Silica/DODAB & 0.05 & $373 \pm 7$ & $33 \pm 2$ & $0.260 \pm 0.02$ \\
\hline $\mathrm{Al}(\mathrm{OH})_{3}{ }^{\mathrm{b}}$ & - & $700 \pm 20$ & $14 \pm 2$ & $0.317 \pm 0.01$ \\
\hline
\end{tabular}

Abbreviations: DODAB, dioctadecyldimethylammonium bromide; PSS, polystyrene sulfate; DTH, delayed-type hypersensibility; BF, bilayer fragments.

ion pairs with dissociated silanol on the silica particle and generating hemolytic effects observed for silica. Adsorption isotherms of 4 different bilayers on hydrophilic silica over a range of experimental conditions helped to clarify this issue. ${ }^{56}$ The separate use of synthetic charged membranes with phosphate or tetraalkylammonium groups as polar heads such as are DODAB and DHP bilayer vesicles, to obtain adsorption isotherms on silica established the relative importance of phosphate or tetraalkylammonium on the mechanism of phospholipid deposition onto hydrophilic silica particles. Formation of ion pairs between the quaternary ammonium in the choline moiety of the phospholipid and the deprotonated silanol drove vesicle adhesion to the particle but vesicle rupture and bilayer deposition was determined by the cooperative occurrence of several hydrogen bridges between silanol and the phosphate moiety on the phospholipid. ${ }^{56}$ There was a low affinity between neutral phospholipids and the silica surface and a high affinity for the cationic amphiphile over a range of $\mathrm{pH}$ values. ${ }^{57}$ Tris-hydroxymethylaminomethane (Tris) used as a buffer increased the affinity between PC and silica at $\mathrm{pH} \leq 7.4$ due to Tris adsorption on silica with an increase in the surface density of hydroxyls on the surface available to hydrogen bridging with phosphate phospholipid groups. Bilayer deposition, however, was unambiguously confirmed by the three techniques only for the interaction DPPC vesicles/silica over 1 hours at $65^{\circ} \mathrm{C}$ and for the interaction DODAB vesicles/silica over the all range of experimental conditions tested. ${ }^{57}$ A simple spectrophotometric method for identifying entire bilayer deposition onto solid particles was developed from incorporation of the optical probe merocyanine 540 onto the outer bilayer vesicle surface. Upon bilayer deposition on the particle, sandwiching the marker between bilayer and solid particle reduced light absorption. Thereby reduction of light absorption by merocyanine was quantitatively related to bilayer deposition. ${ }^{57}$ For the interaction between cationic DODAB/DPPC and anionic PI/DPPC vesicles with zinc citrate dispersions the majority of the adsorption was in the form of intact liposomes. ${ }^{107}$ When liposomes interacted with hydrophilic solid surfaces bearing ionizable groups such as citrate or silanol, the $\mathrm{pH}$ affected the extent of adsorption. ${ }^{107}$ For anionic liposomes, adsorption decreased with $\mathrm{pH}$. For cationic liposomes, adsorption increased with $\mathrm{pH} .{ }^{107}$ The fusion and spreading of phospholipid bilayers on negatively charged glass surfaces was dependent on $\mathrm{pH}$ and ionic strength. ${ }^{108}$ Membrane fusion of negatively charged membranes was favored by low $\mathrm{pH}$ and high ionic strength whereas membrane fusion of positively charged membranes onto the surface occurred under all conditions tested. ${ }^{108}$

\section{The interaction between particles and bilayers for drug delivery}

The particle concept encompasses a broad variety of particulates: lipid particles (eg, a bilayer fragment); polymeric; mineral or metallic particles; bacterial cells; viruses; mammalian cells with several organelles and particles of insoluble, hydrophobic drugs. The lipid covered-latexes were useful as hosts for receptors, ${ }^{60,109,110}$ as coatings reducing protein adsorption on the particles ${ }^{110}$ and in chromatography. ${ }^{111-113}$ The potential of hybrid particle-lipid systems in diagnostics and therapeutics has also been realized. ${ }^{8,114-116}$ In drug formulation, lipid nanoparticles of the anticancer drug chlorambucil were prepared by ultrasonication, using stearic acid as the core lipid and DODAB as surface modifier. ${ }^{117}$ The presence of DODAB on the lipid nanoparticles resulted in greater accumulation of the drug in tumors. ${ }^{117}$ For the encapsulation of cisplatin, bilayer-coating circumvented the limited solubility of cisplatin 
in water and produced cisplatin nanocapsules, bean-shaped nanoprecipitates of cisplatin coated by a lipid bilayer. ${ }^{118}$ The nanocapsules represented a novel lipid formulation of cisplatin characterized by a very high cisplatin-to-lipid ratio and cytotoxicity against tumor cells in vitro as compared to the free drug. The formation of the nanocapsules critically depended on the presence of negatively charged phospholipids and positively charged aqua-species of cisplatin. ${ }^{118,119}$ The effect of PEG on the stability of the cisplatin nanocapsules was studied by incorporating PEG conjugated to phosphatidylethanolamine (DSPE-PEG2000). ${ }^{120}$ Cisplatin release from the nanocapsules depended on the temperature, the surrounding medium, and the lipid composition of the bilayer coat. Sterically stabilized cisplatin nanocapsules containing $6 \mathrm{~mol} \%$ DSPE-PEG served as the starting formulation for in vivo studies addressing the anti-tumor efficacy of cisplatin nanocapsules in tumor-bearing mice; there was a requirement of anionic phospholipid for successful nanoencapsulation of the cationic aqua-cisplatin. ${ }^{120}$

Miconazole or amphotericin B were formulated in DODAB or DHP BF. ${ }^{34,49}$ Some of these formulations required low drug-to-lipid molar ratio due to limited drug loading capacity of the BF at their rims. For example, BF loading capacity for monomeric amphotericin $B$ was $0.1 \mathrm{mM}$ amphotericin $\mathrm{B}$ at $2 \mathrm{mM}$ DODAB meaning that one drug molecule required 20 molecules of cationic lipid to become soluble in the BF nanostructure. At and above this 1:20 drug-to-lipid molar ratio, all solubilization sites at the rim of the BF were occupied. Therefore, further addition of drug resulted in appearance of aggregated amphotericin B in the dispersion as easily monitored by systematic determination of size distribution by means of photon correlation spectroscopy.

In order to formulate hydrophobic drugs with the DODAB lipid at high drug-to-lipid molar ratios, we took advantage of the "sticky" property of chaotropic dihydrogen phosphate anion which converted miconazole or amphotericin B drug particles into negatively charged particles. Thereafter, anionic drug particles could be coated by the DODAB cationic lipid. ${ }^{34,49}$ These formulations were tested against $C$. neoformans and Candida and were very effective due to DODAB activity against fungi. The cationic lipid alone exhibited minimal fungicidal concentrations (MFC) equal to 2 and 2 to $>250 \mathrm{mg} / \mathrm{L}$ against $C$. neoformans and Candida, respectively. In combination, over the first hour, fungicidal activity was due to DODAB with lipid capsules retarding drug action. At 48 hours and $10^{4} \mathrm{cfu} / \mathrm{mL}, \mathrm{MFC}(\mathrm{mg} / \mathrm{L})$ against Candida albicans was reduced from 4 to 1 amphotericin B (at 2 DODAB), and from 8 to 1 miconazole (at 1 DODAB). Calculations of synergism indexes showed synergistic action of both antimicrobial drugs: the cationic DODAB lipid and the microbicidal drug $^{34,49}$ so that the DODAB/miconazole (MCZ) formulations should be further tested regarding therapeutic activity in vivo. Table 3 illustrated the efficacy of MCZ in DODAB or DHP BF despite the low dose of drug.

In summary, two major strategies were developed to formulate hydrophobic drugs with bilayer fragments. These strategies can be better visualized in Figure 4. In Figure 4 (a), coalescence of $\mathrm{BF}$ around the drug granule would encapsulate drug particles at high drug-to-lipid molar ratios. ${ }^{33,34,49,50}$ In Figure 4 (b), monomolecular drug solubilization would be achieved at low drug-to-lipid molar ratios. ${ }^{30,31,33}$ Therefore, these discoidal, charged BF dispersed the hydrophobic drug particles in water both at low and high drug-to-lipid molar ratios.

PEG decorated lipid bilayers are widely used in drug delivery. ${ }^{121}$ In these hybrid polymer/lipid systems, there is a transition from a dispersed lamellar phase (liposomes) to a micellar phase mediated by the formation of small discoidal micelles. The onset of disk formation took place at low PEG-lipid concentrations $(<5 \mathrm{~mol} \%)$ and the size of the disks decreased as more PEG-lipid was added to the lipid mixture. ${ }^{122}$ Stable dispersions dominated by flat bilayer disks could be prepared from a carefully optimized mixture of 1,2-distearoyl-sn-glycero-3-phosphocholine (DSPC), cholesterol, and 1,2-distearoyl-sn-glycero-3-phosphoethanolamine$N$-[methoxy(polyethyleneglycol)-5000][PEG-DSPE(5000)]. By varying the content of PEG-DSPE (5000), the disks diameter varied from about 15 to $60 \mathrm{~nm}$. Disks compared favorably to uni- and multilamellar liposomes for hydrophilic drug partitioning employing immobilized disks in glass capillaries. ${ }^{42}$ The major repulsive interactions preventing fusion of these BF were steric. They provided larger areas

Table 3 Minimal fungicidal concentration (MFC) for Zoltec ${ }^{\circledR}$ (fluconazol), miconazole (MCZ), MCZ/DODAB BF or MCZ/DHP BF against Candida albicans. Copyright ๑ 2006 Elsevier. Adapted with permission from Vieira DB, Pacheco LF, Carmona-Ribeiro AM. Assembly of a model hydrophobic drug into cationic bilayer fragments. J Colloid Interface Sci. 2006;293:240-247.

\begin{tabular}{lll}
\hline Dispersion & \multicolumn{2}{l}{ MFC } \\
\cline { 2 - 3 } & $\mu \mathbf{M}$ & $\mathbf{m g} / \mathbf{m L}$ \\
\hline Zoltec $^{\circledR}$ & 6.5 & 2 \\
DODAB & 4000 & 250 \\
MCZ & 8 & 4 \\
MCZ and DODAB & 2 & 1 \\
MCZ and DHP & 4 & 2 \\
\hline
\end{tabular}

Abbreviations: DODAB, dioctadecyldimethylammonium bromide; PSS, polystyrene sulfate; DTH, delayed-type hypersensibility; BF, bilayer fragments. 

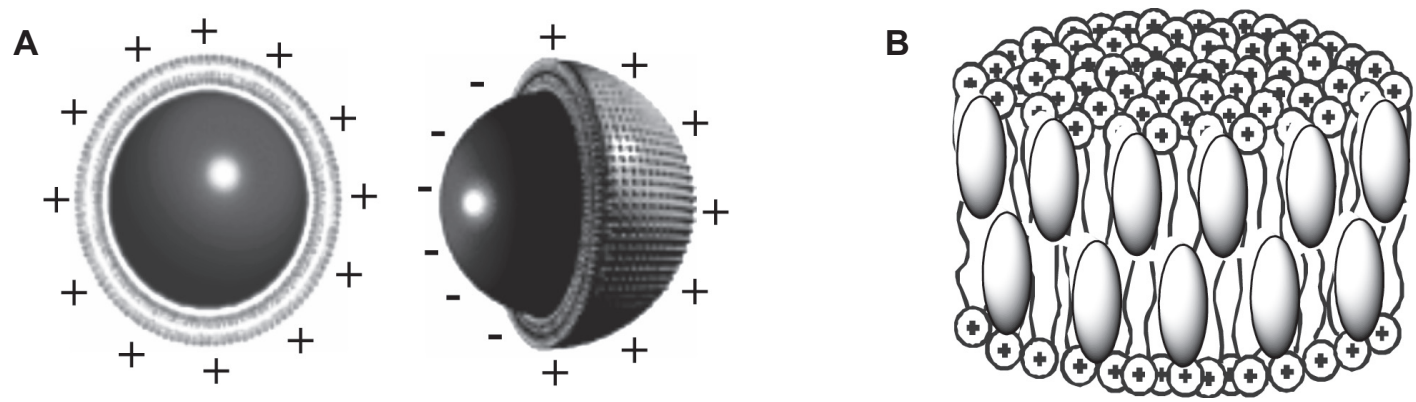

Figure 4 A) Encapsulation of amphotericin B particle by a cationic bilayer at high drug to lipid molar ratio; B) Solubilization of amphotericin B at the rim of cationic BF at low drug to lipid molar ratio.

than vesicles or liposomes for hydrophilic drug partitioning and from this point of view were considered as an attractive and sometimes superior alternative to liposomes. ${ }^{43}$

Reconstitution of receptor-ligand recognition in artificial biomimetic particles is a very promising but hitherto unexplored area for research. The major advantage of these particles is the possibility of complete quantification of binding from simple analytical methods and techniques such as centrifugation for separation between free and bound receptors or free and bound ligands. Aiming at the production of bilayer covered silica particles, the interaction between silica particles and lipid vesicles or BF has been systematically studied by our group since $1997 . .^{56-61}$ As a result optimal coverage of silica particles with a PC bilayer was recently achieved..$^{59,60}$ At $\mathrm{pH}$ 6.3, limiting PC adsorption indicative of one-bilayer deposition on each silica particle was obtained at and above $10 \mathrm{mM} \mathrm{NaCl}$. Increasing ionic strength provided increasing attractive van der Waals attraction between vesicle and particle so that vesicles ruptured upon contact with particles and covered them with one bilayer. ${ }^{59}$ Keeping ionic strength at $10 \mathrm{mM} \mathrm{NaCl}$, the effect of increasing $\mathrm{pH}$ was decreasing affinity between PC and silica. ${ }^{59}$ These experiments revealed an important role for hydrogen bonding between silanol on silica and phosphate on PC driving bilayer deposition. Bilayer deposition improved colloid stability of silica as shown from absence of particulate sedimentation. ${ }^{59}$

Silica-based biomimetic particles successfully immobilized proteins or $\mathrm{DNA}^{13}$ or allowed isolation and reconstitution of receptor-ligand specific interaction. ${ }^{60}$

Cholera toxin (CT) and its receptor, the monosialoganglioside GM1, a cell membrane glycolipid, self-assembled on PC bilayer-covered silica at $1 \mathrm{CT} / 5$ GM1, a molar ratio in perfect agreement with literature. Figure 5 illustrated this proof of concept.

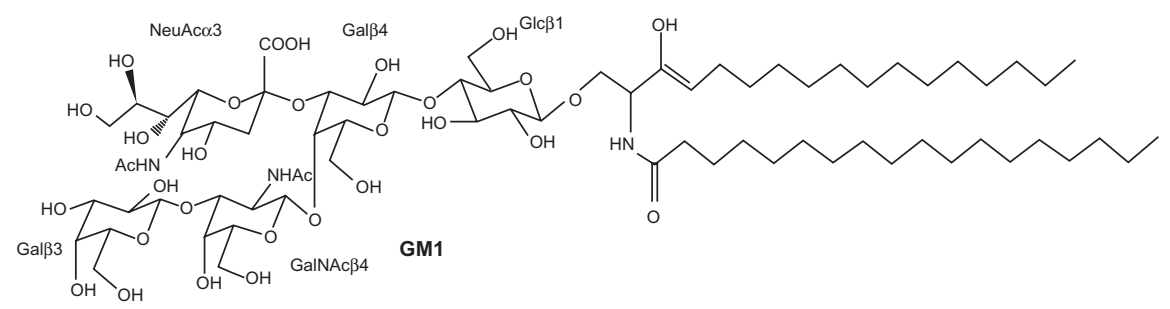
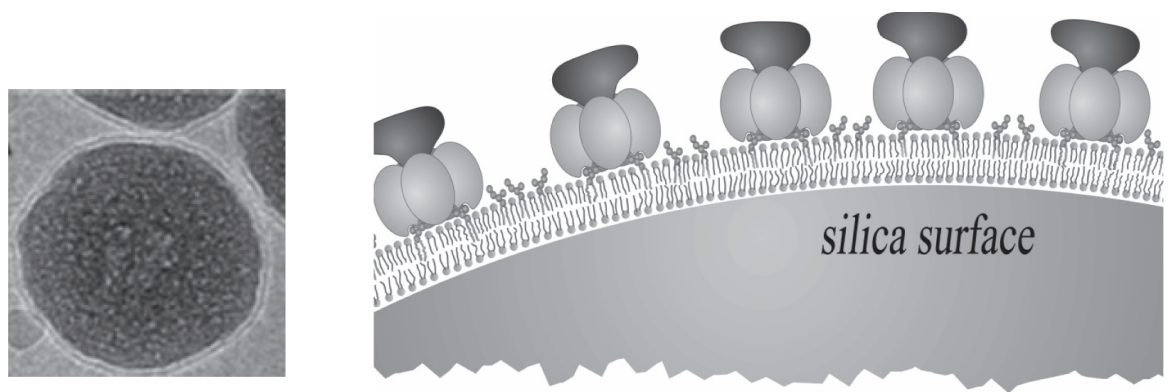

Figure 5 Receptor-ligand recognition on biomimetic particles. ${ }^{60}$ Cryo-TEM revealed the PC bilayer surrounding a silica particle.The GMI receptor inserted in supported PC bilayers recognized its ligand, the cholera toxin. Copyright @ 2005 American Chemical Society.Adapted with permission from Mornet S, Lambert O, Duguet E, Brisson A. The formation of supported lipid bilayers on silica nanoparticles revealed by cryoelectron microscopy. Nano Lett. 2005;5:28I-285

Abbreviations: TEM, transmission electron microscopy; PC, phosphatidylcholine. 


\section{Conclusions}

The intermolecular forces between lipids and particles have to be understood in depth before optimal biomimetic particles based on lipids can be obtained. Over the years our systematic studies on such interactions produced some examples of optimized bilayer deposition on silica or latex particles. Furthermore, charged BF solubilized hydrophobic drugs and complexed with antigens yielding novel supramolecular assemblies for drug and vaccine delivery either by providing hydrophobic edges for drug or antigen complexation or by covering silica, drug or polymeric particles with minute amounts of lipid. Low doses of cationic lipid in the formulations avoided their well described toxicity. Our contribution to the field may be summarized in a thorough description of the differential cytotoxicity of the DODAB cationic lipid, and the invention of novel charged carriers to formulate drugs or vaccines at reduced charged lipid dose. Encapsulation of drugs, reconstitution of biomolecular recognition, antigen presentation and antimicrobial therapy were some examples of biomedical applications for biomimetic particles that were provided by this mini-review.

\section{Acknowledgments}

Financial support from FAPESP and CNPq is gratefully acknowledged.

\section{References}

1. El-Sayed IH, Huang X, El-Sayed MA. Surface plasmon resonance scattering and absorption of anti-EGFR antibody conjugated gold nanoparticles in cancer diagnostics: applications in oral cancer. Nano Lett. 2005;5:829-834.

2. Medintz AR, Clapp JS, Melinger JR, Deschamps H, Mattoussi A. Reagentless Biosensing assembly based on quantum dot-donor Förster resonance energy transfer. Adv Mater. 2005;17:2450-2455.

3. Carmona-Ribeiro AM. Bilayer-forming synthetic lipids: drugs or carriers? Curr Med Chem. 2003;10:2425-2446.

4. O'Hagan DT, Singh M, Ulmer JB. Microparticles for the delivery of DNA vaccines. Immunol Rev. 2004;199:191-200.

5. Caputo A, Sparnacci K, Ensoli B, Tondelli L. Functional Polymeric nano/microparticles for surface adsorption and delivery of protein and DNA vaccines. Curr Drug Delivery. 2008;5:230-242.

6. Moura SP, Carmona-Ribeiro AM. Cationic bilayer fragments on silica at low ionic strength: competitive adsorption and colloid stability. Langmuir. 2003;19:6664-6667.

7. Carmona-Ribeiro AM, Midmore BR. Synthetic bilayer adsorption onto polystyrene microspheres. Langmuir. 1992;8:801-806.

8. Carmona-Ribeiro AM. Biomimetic particles in drug and vaccine delivery. J Liposome Res. 2007;17:165-172.

9. Pereira EMA, Vieira DB, Carmona-Ribeiro AM. Cationic bilayers on polymeric particles: effect of low $\mathrm{NaCl}$ concentration on surface coverage. J Phys Chem B. 2004;108:11490-11495.

10. Carmona-Ribeiro AM. Lipid bilayer fragments and disks in drug delivery. Curr Med Chem. 2006;13:1359-1370.

11. Lincopan N. Carmona-Ribeiro AM. Protein assembly onto cationic supported bilayers. J Nanosci Nanotechnol. 2009;9:3578-3586.

12. Lincopan N, Espíndola NM, Vaz AJ, Carmona-Ribeiro AM. Cationic supported lipid bilayers for antigen presentation. In. J Pharm. 2007;340:216-222.
13. Lincopan N, Espíndola NM, Vaz AJ, et al. Novel immunoadjuvants based on cationic lipid: preparation, characterization and activity in vivo. Vaccine. 2009;27:5760-5771.

14. Lincopan N, Santana MRA, Faquim-Mauro E, da Costa MHB, CarmonaRibeiro AM. Silica-based cationic bilayers as immunoadjuvants. $B M C$ Biotechnol. 2009;9:article 5.

15. Vieira DB, Lincopan N, Mamizuka EM, Petri DFS, CarmonaRibeiro AM. Competitive adsorption of cationic bilayers and chitosan on latex: optimal biocidal action. Langmuir. 2003;19:924-932.

16. Correia FM, Petri DFS, Carmona-Ribeiro AM. Colloid stability of lipid/polyelectrolyte decorated latex. Langmuir. 2004;20:9535-9540.

17. Araujo FP, Petri DFS, Carmona-Ribeiro AM. Colloid stability of sodium dihexadecyl phosphate/poly(diallyldimethylammonium chloride) decorated latex. Langmuir. 2005;21:9495-9501.

18. Rosa H, Petri DFS, Carmona-Ribeiro AM. Interactions between bacteriophage DNA and cationic biomimetic particles. J Phys Chem B. 2008;112:16422-16430.

19. Bangham AD. editor. Liposome Letters. London: Academic Press; 1983. p. $1-405$.

20. Kunitake T, Okahata Y, Tamaki K, Kumamaru F, Takayanagi M. Formation of the bilayer membrane from a series of quaternary ammonium salts. Chem Lett. 1977;6:(4):387-390.

21. Hargreaves WR, Deamer DW. Liposomes from ionic, single-chain amphiphiles. Biochemistry. 1978;17(18):3759-3768.

22. Mortara RA, Quina FH. Chaimovich H. Formation of closed vesicles from a simple phosphate diester. Preparation and some properties of vesicles of dihexadecyl phosphate. Biochem Biophys Res Commun. 1978:81:1080-1086.

23. Czarniecki MF, Breslow R. Photochemical probes for model membrane structures. J Am Chem Soc. 1979;101:3675-3676.

24. Suedholter EJR, Engberts JBFN, Hoekstra DJ. Vesicle formation by two novel synthetic amphiphiles carrying micropolarity reporter head groups. J Am Chem Soc. 1980;102:2467-2469.

25. Israelachvili JN, Mitchell DJ, Ninham BW. Theory of self-assembly of lipid bilayers and vesicles. Biochim Biophys Acta. 1977;470:185-201.

26. Carmona-Ribeiro AM, Yoshida LS, Sesso A, Chaimovich H. Permeabilities and stabilities of large dihexadecylphosphate and dioctadecyldimethylammonium chloride vesicles. J Colloid Interface Sci. 1984;100: 433-443.

27. Carmona-Ribeiro AM, Castuma CE, Sesso A, Schreier S. Bilayer structure and stability in dihexadecyl phosphate dispersions. $J$ Phys Chem. 1991;95:5361-5366.

28. Fuhrhop JH, Fritsch D. Bolaamphiphiles form ultrathin, porous and unsymmetric monolayer lipid membranes. Acc Chem Res. 1986;19: $130-137$.

29. Segota S, Tezak D. Spontaneous formation of vesicles. Adv Colloid Interface Sci. 2006;121:51-75.

30. Vieira DB, Carmona-Ribeiro AM. Synthetic bilayer fragments for solubilization of amphotericin B. J Colloid Interface Sci. 2001;244: $427-431$.

31. Lincopan N, Mamizuka EM, Carmona-Ribeiro AM. In vivo activity of a novel amphotericin B formulation with synthetic cationic bilayer fragments. J Antimicrob Chemother. 2003;52:412-418.

32. Lincopan N, Mamizuka EM, Carmona-Ribeiro AM. Low nephrotoxicity of an effective amphotericin B formulation with cationic bilayer fragments. J Antimicrob Chemother. 2005;55:727-734.

33. Pacheco LF, Carmona-Ribeiro AM. Effects of synthetic lipids on solubilization and colloid stability of hydrophobic drugs. $J$ Colloid Interface Sci. 2003;258:146-154.

34. Lincopan N, Carmona-Ribeiro AM. Lipid-covered drug particles: combined action of dioctadecyldimethylammonium bromide and amphotericin B or miconazole. J Antimicrob Chemother. 2006;58: 66-75.

35. Finer EG, Flook AG, Hauser H. Mechanism of sonication of aqueous egg yolk lecithin dispersions and nature of the resultant particles. Biochim Biophys Acta. 1972;260:49-58.

36. Nath A, Atkins WM, Sligar SG. Applications of phospholipid bilayer nanodiscs in the study of membranes and membrane proteins. Biochemistry. 2007;46:2059-2069. 
37. Bayburt TH, Sligar SG. Single-molecule height measurements on microsomal cytochrome P450 in nanometer-scale phospholipid bilayer disks. Proc Natl Acad Sci U S A. 2002;99:6725-6730.

38. Lyukmanova EN, Shenkarev ZO, Paramonov AS, et al. Lipid-protein nanoscale bilayers: a versatile medium for NMR investigations of membrane proteins and membrane-active peptides. J Am Chem Soc. 2008;130:2140-2141.

39. Hazelbauer GL, Falke JJ, Parkinson JS. Bacterial chemoreceptors: high-performance signaling in networked arrays. 2008;33:9-19.

40. Lawaczeck R, Kainosho M, Chan SI. The formation and annealing of structural defects in lipid bilayer vesicles. Biochim Biophys Acta. 1976; 443:313-330.

41. Almgren M. Mixed micelles and other structures in the solubilization of bilayer lipid membranes by surfactants. Biochim Biophys Acta. 2000;1508:146-163.

42. Johansson E, Engvall C, Arfvidsson M, Lundahl P, Edwards K. Development and initial evaluation of PEG-stabilized bilayer disks as novel model membranes. Biophys Chem. 2005;113:183-192.

43. Johansson E, Lundquist A, Zuo S, Edwards K. Nanosized bilayer disks: attractive model membranes for drug partition studies. Biochim Biophys Acta. 2007; 1768:1518-1525.

44. Pansu RB, Arrio B, Roncin J, Faure J. Vesicles versus membrane fragments in DODAC suspensions. J Phys Chem. 1990;94:796-801.

45. Andersson M, Hammarstrom L, Edwards K. Effect of bilayer phase transitions on vesicle structure, and its influence on the kinetics of viologen reduction. J Phys Chem. 1995;99(39):14531-14538.

46. Meyer HW, Richter W, Rettig W, Stumpf M. Bilayer fragments and bilayered micelles (bicelles) of dimyristoylphosphatidylglycerol (DMPG) are induced by storage in distilled water at $4^{\circ} \mathrm{C}$. Colloids Surf A: Physicochem Eng Aspects. 2001;183-185:495-504.

47. Carmona-Ribeiro AM, Chaimovich H. Preparation and characterization of large dioctadecyldimethylammonium chloride liposomes and comparison with small sonicated vesicles. Biochim Biophys Acta. 1983;733:172-179.

48. Cocquyt J, Olsson U, Olofsson G, van der Meeren P. Temperature quenched DODAB dispersions: fluid and solid state coexistence and complex formation with oppositely charged surfactant. Langmuir. 2004;20:3906-3912.

49. Vieira DB, Pacheco LF, Carmona-Ribeiro AM. Assembly of a model hydrophobic drug into cationic bilayer fragments. J Colloid Interface Sci. 2006;293:240-247.

50. Vieira DB, Carmona-Ribeiro AM. Cationic nanoparticles for delivery of amphotericin B: preparation, characterization and activity in vitro. J Nanobiotechnol. 2008;6:article 6.

51. Carmona-Ribeiro AM. Synthetic amphiphile vesicles. Chem Soc Rev. 1992;21:209-214.

52. Israelachvili JN. Intermolecular and surface forces. 2nd ed. London; Academic Press Limited: 1992.

53. Tsuruta LR, Lessa MM, Carmona-Ribeiro AM. Interactions between dioctadecyldimethylammonium chloride or bromide bilayers in water. Langmuir. 1995;11:2938-2943.

54. Tsuruta LR. Lessa MM. Carmona-Ribeiro AM. Effect of particle size on colloid stability of bilayer-covered polystyrene microspheres. J Colloid Interface Sci. 1995;175:470-475.

55. Tsuruta LR, Carmona-Ribeiro AM. Counterion effects on colloid stability of cationic vesicles and bilayer-covered polystyrene microspheres. J Phys Chem. 1996;100:7130-7134.

56. Rapuano R, Carmona-Ribeiro AM. Physical adsorption of bilayer membranes on silica. J Colloid Interface Sci. 1997;193:104-111.

57. Rapuano R, Carmona-Ribeiro AM. Supported bilayers on silica. J Colloid Interface Sci. 2000;226:299-307.

58. Carmona-Ribeiro AM, Lessa MM. Interactions between bilayer vesicles and latex. Colloids Surf A. 1999;153:355-361.

59. Moura SP, Carmona-Ribeiro AM. Biomimetic particles: optimization of phospholipid bilayer coverage on silica and colloid stabilization. Langmuir. 2005;21:10160-10164.
60. Moura SP, Carmona-Ribeiro AM. Biomimetic particles for isolation and reconstitution of receptor function. Cell Biochem Biophys. 2006;44: 446-452.

61. Moura SP, Carmona-Ribeiro AM. Adsorption behavior of DODAB/ DPPC vesicles on silica. J Colloid Interface Sci. 2007;313:519-526.

62. Horn RG. Direct measurement of the force between two lipid bilayers and observation of their fusion. Biochim Biophys Acta. 1984;778: 224-228.

63. Lin LC, Weis RM, McConnell HM. Induction of helical liposomes by $\mathrm{Ca}^{2+}$-mediated intermembrane binding. Nature. 1982;296:164-165.

64. Jackson S, Reboiras MD, Lyle IG, Jones MN. Adsorption of phospholipid vesicles on solid surfaces. Faraday Discuss Chem Soc. 1986;81: 291-301.

65. Brian AA, McConnell HM. Allogeneic stimulation of cytotoxic T cells by supported planar membranes. Proc Natl Acad Sci U S A. 1984;81: 6159-6163.

66. Tamm LK, McConnell HM. Supported phospholipid bilayers. Biophys J. 1985;47:105-113.

67. Nollert P, Kiefer H, Jaehnig F. Lipid vesicle adsorption versus formation of planar bilayers on solid surfaces. Biophys J. 1995;69:1447-1455.

68. Charitat T, Bellet-Amalric E, Fragneto G, Graner F. Adsorbed and free lipid bilayers at the solid-liquid interface. Eur Phys J B. 1999;8: 583-593.

69. Tápias GN, Sicchierolli SM, Mamizuka EM, Carmona-Ribeiro AM. Interactions between cationic vesicles and Escherichia coli. Langmuir. 1994;10:3461-3465.

70. Martins LMS, Mamizuka EM, Carmona-Ribeiro AM. Cationic vesicles as bactericides. Langmuir. 1997;13:5583-5587.

71. Carmona-Ribeiro AM, Ortis F, Schumacher RI, Armelin MCS. Interactions between cationic vesicles and cultured mammalian cells. Langmuir. 1997;13:2215-2218.

72. Campanhã MTN, Mamizuka EM, Carmona-Ribeiro AM. Interactions between cationic vesicles and Candida albicans. J Phys Chem B. 2001; 105:8230-8236

73. Campanhã MTN, Mamizuka EM, Carmona-Ribeiro AM. Interactions between cationic liposomes and bacteria: the physical-chemistry of the bactericidal action. J Lipid Res. 1999;40:1495-1500.

74. Gall D. The adjuvant activity of aliphatic nitrogenous bases. Immunology. 1966;11:369-386.

75. Dailey MO, Hunter RL. The role of lipid in the induction of haptenspecific delayed hypersensitivity and contact sensitivity. J Immunol. 1974;112:1526-1534.

76. Hilgers LA, Snippe H, DDA as an immunological adjuvant. Res Immunol. 1992;143:494-503.

77. Tsuruta LR, Quintilio W, Costa MHB, Carmona-Ribeiro AM. Interactions between cationic liposomes and an antigenic protein: the physical chemistry of the immunoadjuvant action. 1997;38:2003-2011.

78. Klinguer-Hamour C, Libon C, Plotnicky-Gilquin H, et al. DDA adjuvant induces a mixed $\mathrm{Th} 1 / \mathrm{Th} 2$ immune response when associated with BBG2Na, a respiratory syncytial virus potential vaccine. Vaccine. 2002;20:2743-2751.

79. Korsholm KS, Agger EM, Foged C, et al. The adjuvant mechanism of cationic dimethyldioctadecylammonium liposomes. Immunology. 2007;121:216-226.

80. Gregoriadis G, McCormack B, Obrenovic M, Saffie R, Zadi B, Perrie Y. Vaccine entrapment in liposomes. Methods. 1999;19:156-162.

81. Perrie Y, Mohammed AR, Kirby DJ, McNeil SE, Bramwell VW. Vaccine adjuvant systems: enhancing the efficacy of sub-unit protein antigens. Int J Pharm. 2008;364:272-280.

82. O'Hagan DT, Singh M. Microparticles as vaccine adjuvants and delivery systems. Expert Rev Vaccines. 2003;2:269-283.

83. Xiang SD, Scholzen A, Minigo G, et al. Pathogen recognition and development of particulate vaccines: Does size matter? Methods. 2006;40:1-9.

84. Gupta R. Aluminum compounds as vaccine adjuvants. Adv Drug Delivery Rev. 1998;32:155-172. 
85. Jefferson T, Rudin M, Di Pietrantonj C. Adverse events after immunisation with aluminium-containing DTP vaccines: systematic review of the evidence. Lancet Infectious Diseases. 2004;4:84-90.

86. Clements C, Griffiths E, Clements C, Griffiths E. The global impact of vaccines containing aluminium adjuvants. Vaccine. 2002;20: S24-S33.

87. Trollfors B, Bergfors E, Inerot A. Vaccine related itching nodules and hypersensitivity to aluminium. Vaccine. 2005;23:975-976.

88. Lindblad E. Aluminium adjuvants-in retrospect and prospect. Vaccine. 2004;22:3658-3668.

89. Gupta R, Siber G. Adjuvants for human vaccines - current status, problems and future prospects. Vaccine. 1995;13:1263-1276.

90. Singh M, Ugozzoli M, Kazzaz J, et al. A preliminary evaluation of alternative adjuvants to alum using a range of established and new generation vaccine antigens. Vaccine. 2006;24:1680-1686.

91. Singh M, O’Hagan D. Advances in vaccine adjuvants. Nature Biotechnology. 1999;17:1075-1081.

92. Ott G, Barchfeld G, Chernoff D, Radhakrishnan R, van Hoogevest P, Van Nest G. MF59. Design and evaluation of a safe and potent adjuvant for human vaccines. Pharm Biotechnol. 1995;6:277-296.

93. Traquina P, Morandi M, Contorni M, Van Nest G. MF59 adjuvant enhances the antibody response to recombinant hepatitis B surface antigen vaccine in primates. J Infect Dis. 1996;174:1168-1175.

94. Granoff D, McHugh Y, Raff H, Mokatrin A, Van Nest G. MF59 adjuvant enhances antibody responses of infant baboons immunized with Haemophilus influenzae type b and Neisseria meningitis group C oligosaccharide-CRM197 conjugate vaccine. Infect Immun. 1997;65: 1710-1715.

95. Podda A, Del Giudice G. MF59-adjuvanted vaccines: increased immunogenicity with an optimal safety profile. Expert Rev Vaccines. 2003; 2:197-203.

96. Cusi M. Applications of influenza virosomes as a delivery system. Hum Vaccin. 2006;2:1-7.

97. Glück R, Burri K, Metcalfe I. Adjuvant and antigen delivery properties of virosomes. Curr Drug Deliv. 2005;2:395-400.

98. Huckriede A, Bungener L, Stegmann T, et al. The virosome concept for influenza vaccines. Vaccine. 2005;23:S26-S38.

99. Baldrick P, Richardson D, Wheeler A. Review of L-tyrosine confirming its safe human use as an adjuvant. J Appl Toxicol. 2002;22:333344.

100. Kovacsovics-Bankowski M, Clark K, Benacerraf B, Rock KL. Efficient major histocompatibility complex class I presentation of exogenous antigen upon phagocytosis by macrophages. Proc Natl Acad Sci U S A. 1993;90:4942-4946.

101. Vidard L, Kovacsovics-Bankowski M, Kraeft SK, Chen LB. Benacerraf B, Rock KL. Analysis of MHC class II presentation of particulate antigens of B lymphocytes. J Immunol. 1996;156:2809-2818.

102. Foged C, Brodin B, Frokjaer S, Sundblad A. Particle size and surface charge affect particle uptake by human dendritic cells in an in vitro model. Int J Pharm. 2005;298:315-322.

103. Osaka T, Nakanishi T, Shanmugam S, Takahama S, Zhang H. Effect of surface charge of magnetite nanoparticles on their internalization into breast cancer and umbilical vein endothelial cells. Colloids and Surf B: Biointerfaces. 2009;71(2):325-330.

104. Carmona-Ribeiro AM, Vieira DB, Lincopan N. Cationic surfactants and lipids as anti-infective agents. Anti-Infective Agents in Medicinal Chemistry. 2006;5:33-51.

International Journal of Nanomedicine

\section{Publish your work in this journal}

The International Journal of Nanomedicine is an international, peerreviewed journal focusing on the application of nanotechnology in diagnostics, therapeutics, and drug delivery systems throughou the biomedical field. This journal is indexed on PubMed Central, MedLine, CAS, SciSearch $\AA$, Current Contents $₫ /$ Clinical Medicine,
105. Carmona-Ribeiro AM. Bilayer vesicles and liposomes as interface agents. Chem Soc Rev. 2001;30:241-247.

106. Nash T, Allison AC, Harington JS. Physico-chemical properties of silica in relation to its toxicity. Nature. 1966;210:259-261.

107. Catuogno C, Jones MN. The interaction of cationic and anionic vesicles with zinc citrate dispersions. Colloids Surf A. 2000;163:165-176.

108. Cremer PS, Boxer SG. Formation and spreading of lipid bilayers on planar glass supports. J Phys Chem. 1999;103:2554-2559.

109. Sicchierolli SM, Carmona-Ribeiro AM. Incorporation of the cholera toxin receptor in phospholipid-covered polystyrene microspheres. Colloids and Surf B: Biointerfaces. 1995;5:57-64.

110. Sicchierolli SM, Carmona-Ribeiro AM. Biomolecular recognition at phospholipid-covered polystyrene microspheres. J Phys Chem. 1996;100:16771-16775.

111. Hautala JT, Linden MV, Wiedmer SK, et al. Simple coating of capillaries with anionic liposomes in capillary electrophoresis. J Chromatogr A. 2003;1004:81-90.

112. Haratake M, Hidaka S, Ono M, Nakayama M. Preparation of an ion-exchangeable polymer bead wrapped with bilayer membrane structures for high performance liquid chromatography. Anal Chim Acta. 2007;589:76-83.

113. Gulcev MD, Lucy CA. Factors affecting the behavior and effectiveness of phospholipid bilayer coatings for capillary electrophoretic separations of basic proteins. Anal Chem. 2008;80:1806-1812.

114. Al-Jamal WT, Kostarelos K. Liposome-nanoparticle hybrids for multimodal diagnostic and therapeutic applications. Nanomedicine. 2007;2:85-98.

115. Singh R, Tian B, Kostarelos K. Artificial envelopment of nonenveloped viruses: enhancing adenovirus tumor targeting in vivo. FASEBJ. 2008;22:3389-3402.

116. Soo PL, Dunne M, Liu J, Allen C. Nano-sized advanced delivery systems as parenteral formulation strategies for hydrophobic anti-cancer drugs. In: Biotechnology: Pharmaceutical Aspects, de Villiers MM. Aramwit P. Kwon GS, editors. Heidelberg: Springer; 2009. p. 349-383.

117. Sharma P, Ganta S, Denny WA, Garg S. Formulation and pharmacokinetics of lipid nanoparticles of a chemically sensitive nitrogen mustard derivative: Chlorambucil. Int J Pharm. 2009;367:187-194.

118. Burger KN, Staffhorst RW, de Vijlder HC, et al. Nanocapsules: lipid-coated aggregates of cisplatin with high cytotoxicity. Nature Medicine. 2002;8:81-84.

119. Chupin V, de Kroon AIP, de Kruijff B. Molecular architecture of nanocapsules, bilayer-enclosed solid particles of cisplatin. J Am Chem Soc. 2004; 126:13816-13821.

120. Velinova MJ, Staffhorst RW, Mulder WJ, et al. Preparation and stability of lipid-coated nanocapsules of cisplatin: anionic phospholipid specificity. Biochim Biophys Acta. 2004;1663:135-142.

121. Lasic DD. Sterically stabilized vesicles. Angew Chem Int Ed Engl. 1994;33(17):1685-1683.

122. Johnsson M, Edwards K. Liposomes, disks, and spherical micelles: aggregate structure in mixtures of gel phase phosphatidylcholines and poly(ethylene glycol)-phospholipids. Biophys J. 2003;85:3839-3847.

123. Mornet S, Lambert O, Duguet E, Brisson A. The formation of supported lipid bilayers on silica nanoparticles revealed by cryoelectron microscopy. Nano Lett. 2005;5:281-285.

Journal Citation Reports/Science Edition, EMBase, Scopus and the Elsevier Bibliographic databases. The manuscript management system is completely online and includes a very quick and fair peer-review system, which is all easy to use. Visit http://www.dovepress.com/ testimonials.php to read real quotes from published authors. 